\title{
PEDAGOGICAL ASPECTS OF LOGARITHMIC AND RHYTHMTHERAPY ON THE DISORDERS OF FLUENCY AND THEMPO-RHYTHMIC ORGANIZATION OF SPEECH OR STUTTERING
}

\author{
B. Petrova* \\ DIIT, Trakia University, Stara Zagora, Bulgaria
}

\begin{abstract}
The relationship between logarithmic and rhythm therapy is multifaceted, which explains the good opportunities for their application in a primary school in students with fluency and tempo-rhythmic organization of speech, which form the picture of development- stuttering. Research related to the pedagogical aspects of this application is relevant, as the problem is analyzed mainly theoretically as related to other scientific fields. This article presents methods for corrective work, which is also the concept of this framework of speech therapy rhythmic: object, subject, goal and tasks. A theoretical analysis on the topic was made and a study of the role of logarithmic and rhythm therapy from the point of view of pedagogues in primary school was presented.

The results are analyzed in terms of their applicability and adequacy to the learning process and pedagogical practice.
\end{abstract}

Key words: logarithmic technologies, rhythm, stuttering

\section{INTRODUCTION}

In present times the modern information world, verbal communication continues to be an important way of communication. Verbal communication between people is thanks to their specific speech activity. It can be: speaking, listening (or even listening with comprehension), reading and writing. Depending on whether a certain piece of information is reproduced or only perceived, as well as on the way the communicative act is performed, the indicated speech activities participate in it in a different way. Assimilation is not directly proportional for all children and on the other hand, it is also not easily accessible, the acquisition of fluent speech activity. Based on the analysis of various data on oral speech disorders in primary school age, I. Yu. Abeleeva (1) oncludes that stuttering occurs during the transition from the phase of readiness to the phase of realization of the speech. Developing this point of view I. Yu. Abeleeva (1) notes that stuttering is a breach of the readiness for speech in the presence of the speaker and communicative intention, and

\footnotetext{
*Correspondence to: Borislava Petrova, DIIT, Trakia University, Stara Zagora, Bulgaria
}

the program of speech, and the fundamental ability to speak normally. Defining stuttering as a general neurosis, according to N.I. Jinkin (2) this is the starting point of manifestation only and most clearly in speech.

Another author, M.I.Paykin (3), studied the mechanism and nature of stuttering in early childhood, found in it: "pathological, combined reflex, brought up by the environment on the basis of early speech automatisms."

Focusing on oral speech and in particular on a characteristic stuttering disorder (stuttering) is that among the numerous speech disorders stuttering occupies a special place-stuttering is the most common.

On one hand, this disorder does not belong to the category of the most severe speech disorders, because it does not prevent a person from performing his social functions, i.e. does not cause damage, unlike, for example, aphasia, dysarthria due to cerebral palsy. On the other hand, it often serves as a manifestation of more severe central nervous system functions, which as they develop over time, can lead to significant disability. The 
research presented answers the question to what extent does working with logarithm and rhythm therapy affect stuttering. A survey among pedagogical specialists was conducted.

\section{METODOLOGY}

The methodological framework through which the goal is achieved consists of 3 tasks. First, the preparation of a survey that provides statistically accurate information about the application of logarithmic technologies and rhythm therapy in overcoming stuttering. Second, the total numbers of responses, two types identified by $\mathrm{t}$-Test stand out and are identified. Third, a hypothesis is formulated between the answers to these specific questions.

\section{Theoretical review}

The first scientific ideas about communication disorders originated in ancient Greece and Rome. Herodotus, considered today the "father" of history, was one of the first scholars to mention speech disorders. Describing the broken speech of the Cyrene king Batos (Bata), he is talking about stuttering. It is believed that the term batarism used in some of speech therapy literature originates from the name of King Batos, which according to Herodotus is only a nickname derived from stuttering, and the real name of the King Alexander. Despite the controversy over the meaning of the term battery life, it is believed that it represents precisely the concept of impaired speech. Another ancient Greek scholar mentions speech disorders in his writings was Hippocrates. He uses specific names that sound like a diagnosis, one of which is ischonophonia (stuttering). With this name Hippocrates defines speech behavior, which is a specific, unconscious and forced repetition of syllables, which largely overlaps with today's notions of stuttering. Aristotle uses the same term as Hippocrates, explaining that stuttering is a problem that is associated with the movement of the tongue and in particular the difficulty of moving the language when it has to switch from one position to another. Aristotle added that stuttering is more common in children than in adults due to the still poorly developed control over the tongue. Plutarch, on the other hand, gives detailed information about stuttering, describing the presence of the disease in one of the known personalities of antiquity, stuttering from stuttering- Demosthenes. The irony is that Demosthenes is known as an ancient Greek orator, tribune and politician who managed to overcome stuttering. In the history of speech therapy, this is considered a remarkable case, and Demosthenes himself managed to get rid of the speech disorder by creating a system of exercises to influence speech. The Romans inherited ancient Greek culture and knowledge. Aul Cornelius Celsus, for example, points to impaired mobility or abnormal language structure as the cause of speech disorders. Galen points out that the main causes of speech disorders are due to damage to the central nervous system. Based on what has been said so far, we can summarize that ancient Greece and Rome marked the beginning of the development of medical science in the fielld of speech therapy. Tsenova (4)

Disorders of the tempo-rhythmic organization of speech, due to the convulsive state of the speech apparatus, in our time, are called stuttering. The doctrine of stuttering has a long history and a contradictory path of development. We start with the terminological name of the whole group of speech anomalies (dysprosodia). At the moment, there is no common name. The analysis of the anomalies shows that in each of the anomalies there is a deviation mainly in prosodic componentstempo and smoothness. The language system is defective only in the realm of prosody, and it is an element and exists only in the process of speaking.

According to Stamov, V. (5) the subgroup of dysprosodia includes two main types: anomalies of tempo (dystempotia). In turn, disfluencies subdivided into stating (stuttering) and stammering (stuttering). The main phenomenon of stuttering is a spasm. The analysis of N. I. Jinkin (2) shows that "There is a single trigger pulse in the premotor area at the pre-start moment to pronounce. It splits along the pyramidal paths. During start-up, the extrapyramidal impulse weakens significantly.“

This condition is not due to intellectual or sensory impairments; it affects children in the psycho-physical norm, for whom impaired ability to verbal communication is the only problem.

R. M. Boskis (6) Bo connects stuttering with the underdevelopment of children speech, calling it a disease "which is based on speech difficulties associated with the design of more 
or less complex statements that require phrases to express them."

Speech difficulties, according to her, can be caused by delays in speech development (related to languages, grammar, insufficient vocabulary, pathological pronunciation development: interdental speech, tachylalia, rhinolalia), switching to another language, cases of pathological development of the person with under development of the emotional volitional sphere, etc. the need to express a complex thought, etc. The beginning of stuttering is usually determined in the period of intensive formation of speech function, i.e. two-six years old children.

Statistic on the prevalence of stuttering is highly controversial. It shows an average of about two-percent of children and not much more than one-percent adults suffering from stuttering. With regard to determining the causes of stuttering, it should be emphasized that there is no specific single cause of this speech disorder, as this requires a combination of a number of factors. In common to distinguish between two groups of cause predisposing ("soil") and producing ("tremor"). At the same time, some etiological factors can both contribute to the development of stuttering and directly cause it.

The predisposing causes include: neuropathic load on parents, neurological features of the most stuttering, hereditary severity, brain damage in the prenatal, natal and postnatal period, natal and postnatal periods of development. In the group of causative agents are distinguished: anatomical, physiological, mental and social. The problems of stuttering have also been developed in our country (St. Tonchev, P. Mednikarov, D. Denev, D. Daskalov, K. Kandov, V. Ivanov, and others). Everyone's efforts are focused on finding effective ways to overcome the launch.

A controversial and controversial issue is the definition of the mechanism of stuttering, which since ancient times has been viewed differently by proponents of the psychological direction, such as Christopher Lagusen (7). According to others, William A. Cohen (1878), Netkachev (1909, 1913), E. Frelzes, Yu. A. Florenskaya (8) and other researchers are of the opinion that this type of speech anomaly is caused by violation of the coordination of the speech apparatus. They consider physiological manifestations to be a consequence of psychological defects. Proponents of the pedagogical field (A. Adler, Schneider and others) define stuttering as a consequence of the contradiction between the desire and inability to speak.

On the other hand, the supporters of the physiological trend (G. Gutsman (1879), I. A. Sikorski (1889), and others) believe that stuttering is a neurosis of coordination, i.e. caused by irritable weakness of the central speech apparatus. This weakness leads to abnormal convulsive movements. Later research began to fluctuate between physical and psychological factors as a cause of stuttering. Systematic studies and statics show that it begins most often between the ages of two-five years, practically the time when children begin to actively form their speech abilities.

At present, no links have been found between the intelligence of the child and his stuttering. Statistics also show that boys stuttering between two and four times more often than girls and recover more difficult, which at a later age increases the ratio of stuttering men and women to four to one. Spontaneous recovery is thought to be possible in childhood and especially before starting school, but it is almost unbelievable after the age of 16 . What is special about stuttering is that it affects not only the smoothness of speech, but also the emotional state and behavior of a person in different life situations. Stuttering is often accompanied by additional movements, such as tics and uncontrolled body movements, which are manifested in the violation of smooth speech. Many scholars believe that these movements are the visible expression of the stutterer's inner struggle to utter his words and the anxiety of the interlocutor's reaction.

The unanimous opinion in scientific circles is that stuttering most often occurs in early childhood and, if timely speech therapy intervention is not undertaken, it becomes part of the speech stereotype and affects the overall personality of the stutterer.

A curious historical fact is that many celebrities have suffered from stutteringAesop, Aristotle, Cervantes, Darwin, Newton, Winston Churchill, George Washington, Marilyn Monroe, Madonna and many others.

After the historical review of the first research related to stuttering, it is necessary to mention 
some of the more significant works in this direction from the last two centuries. In 1838, the Russian scientist Laguzen pointed out that the causes of stuttering should not be sought only in the imperfections of the speech organs, but also in various diseases, psychotrauma and the like. In Sikorski's (9) monograph Ön Stuttering", from 1889, stuttering is defined as a childhood disease, the correction of which must be done in early childhood through mental influence. In 1990, Netkachev defined stuttering as a psychoneurosis (Ivanov, Kotsev, 1979). Tartakowski, in 1934 in his work "Psychology of Stuttering and Collective Psychoterapy" advocated unknown small changes in the physiology of the central nervous system, favoring the emergence of mental trauma and affecting the emotionalvolitional sphere. According to him, these changes stabilize the overall mental status of the person, as a result of which, simultaneously with tremor functional disorders of speech, stuttering occurs (Ivanov, Kotsev, 1979).

In the early twentieth century, a variety of news reviews can be summarized in some of the main theoretical areas that are used:

*subconscious manifestation, which is a result of mental traumas, specific conflicts with circumcision on Monday/A. Adler, Shneider/;

*spastic neurosis of coordination/ G. Gutsman, I. A. Kusmaul, I. A. Sikorski/;

*associative disorder of psychological nature /E. Frochels, A. Liebman, G. D. Netkachev/. The World Health Organization defines stuttering as a violation of the speech rhythm, in which the stutterer knows exactly what he wants to say, but at the same time cannot pronounce it correctly, due to involuntary prolongation or interruption of the sound, and hence his speech, violates his ability to express himself and speak at a normal pace. In the International Classification of Diseases (ICD10) stuttering is categorized in the group of the so-called Specific disorders in the development of speech and language. These disorders are defined as disorders in which the normal patterns of language acquisition are violated in the early stages of development."(ICD-10, 2003, P.432).

According to ICD-10, this disorder is defined as a specific articulation disorder that is associated with a specific developmental disorder in which speech use is below the level of the child's mental age, but language skills are at a normal level. (ICD-10,2003). In addition, there is talk of expressive speech disorder, in which the child's ability to use expressive speech is significantly below the appropriate level for his mental age, but language comprehension is within normal limits.(ICD-10, 2003).

Another major source defining speech disorders is the DSM-4 (Diagnostic and Statistical Manual of Mental Disorders), published by America's most influential professional organization of psychiatrists, the American Psychiatric Organization (APA). According to DSM-4, stuttering is a disorder of the normal fluency of the temporal organization of speech (inconsistent with the age of the individual), characterized by frequent spread and affecting: repetitions of sounds and syllables, lengthening of sounds, exclamations, disturbed structure of the word, soundless blockages, detours, spoken words with excessive physical tension, monosyllabic repetitions.

Miglena Simonska, quoting Dobrinka Georgieva, points out as the most defining stuttering the following definition: "Stuttering is considered a difficult remediable violation of the fluidity of speech, which often relapses. Information about it has existed for a long time, as it is widespread enough. It is a scientific, personal and social problem, despite the fact that it is probably the most studied violation compared to the rest of speech and linguistic pathology. (Simonska, 2004)

In general, it can be said that stuttering is a violation of the temporal organization of speech, depending on the state of the muscles of the speech apparatus and their functioning, their formation and the ability of the individual to trigger them in specific situations.

In conclusion of the said can be summarized that stuttering by its nature is characterized by a disruption of the flow of speech from uncoordinated movements of the muscular system of breathing, voice and articulation, which leads to a violation of the entire rhythmic structure of speech. As a spasmodic violation of the pace and rhythm of speech during communication, together with spasmatic inhibitions, accompanying movements appear that accompany stuttering. From what has been said so far, it can be summarized that communicative disorders, and in particular tatting (stuttering), are the result of the dichotomy congenital-acquired. In all 
cases, they affect the development of the child, with a particularly negative influence on the acquired disorders that arise after the speech has already developed.

Rhythm therapy (music therapy) - the therapeutic effect of working with rhythm has a proven effect. At the heart of her is vibration: it is a cyclicality of action and rest.

The concept of applying rhythm therapy is this: everything around us is vibration, the American Music Therapy Association defines music therapy: "clinically and evidence-based use of musical interventions to achieve individual goals within therapeutic relationships. It is administered by a professional who has approved and who has completed an approved music therapy program."

According to Martin Ivanov (10), the founder of the drum, also called rhythm therapy in Bulgaria: "the rhythm is basic and is connected with the first musical instrument, the heart."

Modern studies confirm the therapeutic effect of ancient rhythm techniques.

\section{RESULTS}

In the results of the survey obtained, it is concluded that the pedagogical specialists are not familiar with the foundation of the two above methods. Conceptual framework of speech disorders:

The object of the speech rhythm is a person (child) with speech pathology, an anomaly.

Subjects are the numerous violations of the psychomotor functions of people with speech pathology and the system of movements in combination with music and speech. The goal is to overcome speech disorders through the application of logo rhythmic technologies: a combination of words, music, movements approved to the age characteristics of the object.

The tasks of the speech rhythm are: improving, educational (cognitive), corrective.

Research in this direction has been made by Bulgarian authors, Margarita Stankova, creates and conducts and academic course: Therapy for stuttering-evidence-based practices.

Subsequently, they appear in book.

\section{Analysis of the survey data}

Table1. Linear correlation

t-Test: PairedTwoSamplefo

Means

\begin{tabular}{lrr}
\hline & \multicolumn{1}{c}{ Kod 1 } & \multicolumn{1}{c}{ Koд 2 } \\
\hline Mean & 1,273743 & 1,312849162 \\
Variance & 0,199925 & 0,216182286 \\
Observations & 179 & 179 \\
PearsonCorrelation & $\mathbf{0 , 8 2 8 8 1 2}$ & \\
HypothesizedMeanDifference & 0 & \\
Df & 178 & \\
t Stat & $-1,95673$ & \\
P(T<=t) one-tail & $\mathbf{0 , 0 2 5 9 7 2}$ & \\
t Criticalone-tail & 1,653459 & \\
P $(\mathbf{T}<=$ t) two-tail & $\mathbf{0 , 0 5 1 9 4 3}$ & \\
t Criticaltwo-tail & 1,973381 & \\
\hline
\end{tabular}

We formulate a Ho hypothesis: there is no statistically credible difference between the answer to Questions 4 and 5. The results are presented in Diagrams 1 and 2. Diagram 1 (Question 4: Are you aware of the benefits, opportunities and benefits associated with applying logo rhythmic to students with impaired speech fluidity?)
Diagram 2 (question 5: Are you aware of the benefits, opportunities and benefits associated with applying rhythm therapy to students with impaired speech fluidity?)

By mapping the charts, a conclusion can be drawn about the correlation between the two answers, it is high, and Pearson's coefficient is equal to 0.83 , which means high correlation dependency. 
Are you aware of the benefits, opportunities and benefits associated with applying logo rhythmics to students with impaired speech fluidity?

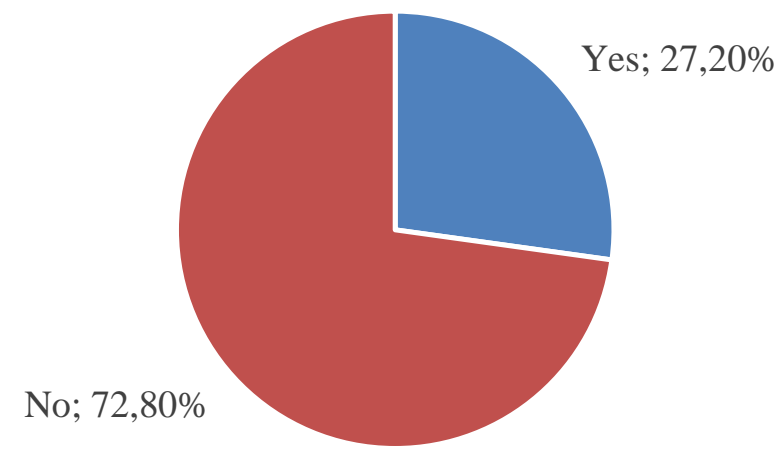

Diagram 1. Application of logarithmic

\section{Are you aware the benefits, opportunities and benefits associated with applying rhythm therapy to students with impaired speech fluidity?)}

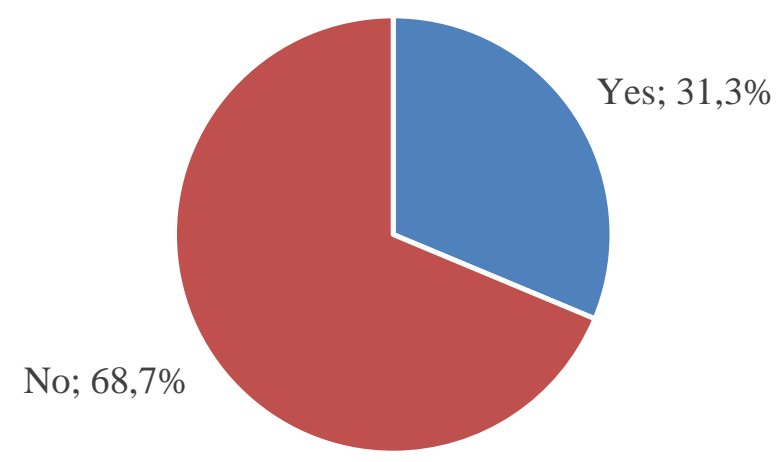

Diagram 2. Application of rhythm therapy

T-test gives to cheek the unilateral hypothesis $\mathrm{P}$-value $=0,003$, which is 0,05 . This suggests that the unilateral hypothesis with the average value of one response is higher than the other is rejected. However, we do not have sufficient grounds that there is a statistically credible difference, since for the two-way hypothesis p-VALUE $=0,052$ IS 0,05 , in order to obtain a basis for general conclusions, for these two groups of knowledge it is necessary to increase the number of persons examined.

Statistics show that $55,9 \%$ of those who completed the survey were primary school teachers. It is clear from the survey that according to the observations of the pedagogical specialists that the work with a logo rhythm is not implemented in the educational content. In these results there is a reflection on the level of teacher training. It shows, in turn, that the two methods are equally unknown and not applicable in practice to teachers. This is the reason for a recommendation, to include logo rhythmic and rhythm therapy in the future curricula of educators.

\section{CONCLUSION}

The multi-dimensional nature of stuttering as a fluid disorder, and in particular the links 
between physiological, psychosocial, and psycholinguistic factors, also suggest the involvement of a large number of specialists and researchers to be involved in the development of new diagnostic procedures and therapeutic techniques. One of the main tasks of the logo rhythm is the elimination of speech disorders, solving the problem of speech development.

In the survey conducted, pedagogical specialists interpret the application of logo rhythmic and rhythm therapy in view of their importance in overcoming stuttering and applying them in practice. The facts speak of results, which in synthesized form are:

-Is the work with a logo rhythmic embedded in the learning content? - 82\%-no

-Are you familiar with the benefits, opportunities and benefits associated with applying:

-logo rhythmic: 72,8\%-no

-rhythm therapy: 68,7\%-no

This shows that these methods are unknown among the pedagogical socialists in the country, although they have proven their effectiveness globally.

It is therefore necessary to completely restructure the curricula in higher education institutions and, above all, to focus on its practical implementation, to place students in different situations, not only in the classroom, where they use learned speech practices and skills. And as it is known, the develop skills for using the whole stock of language tools in accordance with the norms of literary speech and specifics of the speech situation-are an important prerequisite for the development speech.

Speech therapy training is a dynamic process and its application is not carried out in the classroom system, among the surveyed teachers. The recommendation to them is not to do it dogmatically, but to follow the sequence of stage. Depending on the degree and form of stuttering, some of the stages may be shortened or lengthened. It is important to point out that the overcoming of stuttering is carried out in three main directions: methodical/speech therapy training, psychotherapy and medical treatment.

Mechanical means have been sought and are being sought to overcome this speech challenge. Electronic devices are very important in conducting therapies to increase speech fluency in stuttering The VoceAmp VA 601 device supports fluent speech in nearly 80 percent of stuttering.

In general, the conclusion from the results of the survey is that pedagogical specialists note the lack of logarithmic in the curriculum. Therefore, although, at present, logarithmic and rhythm therapy is not applied, it is clear from the end result that they are necessary methods to overcome one of the fluency disorders, namely stuttering.

\section{REFERENCES}

1. Abeleva, I.Yu. Psychology of stuttering in adults in different phases og the process of verbal communication/Psychology.1974

2. Zhinkin, I. Psychological basis of speech development, Moscow, 1998

3. Paykin,M.I. For systematic nailing/Secular psychoneurology.-.M.,1932

4. Tsenova, Tsevetanka. Fundamentals of speech therapy, IM "St.Kliment Ohridski", 2012

5. Stamov, V. (1989).Logopedia. Higher Pedagogical Institute, Blagoevgrad

6. Boskis,R.M., On the nature and treathment of stuttering in personal children. Treathment of the mentaly ill: Collection of scientific papers. M., 1940

7. Lagusen, Christopher. On stuttering., M., 1938

8. Florenskaya,Yu.A.Reverse development in the process of treathment trough the collective psychological method and residual symptoms. Bio Publishing house, issue 1,1935

9. Sikorski, I.A..About stuttering, Carl Reeker Edition, 1889

10.Ivanov, M. Alchemy of rtythm in serch of the philosopher's stone. Ed.Lyk, Sofia, 2012

11. Boyanova, V. From the symptom to the diagnosis in speech pediatric practice. Nbu.Sofia, 2012

12.Van Borsell, J. Acquired stuttering: overview.In: Georgieva, D. Violations of the fluidity of speech. New research perspectives. Ed Graffiti, Sofia, 2004

13.Volkova, G.A.(2002). Speech rhythm (Correctional Pedagogy), M: Humanity. Ed. VLADOS Center

14.Georgieva, D. Stuttering Theories: Overview.In: Georgieva, D. Violations of the fluidity of speech. New research perspectives .Ed."'Graffiti”, Sofia , 2004 
15.Ivanov, V., Kotsev, G. Correction of speech deficiencies in children. Di People's Education. Sofia, 1979

16.Stankova, M. Stuttering therapy programs, evidence-based practices, ed. NBU,2007

17.Stankova, M.Social phobia and stuttering, compendium of Logopedia and Foniateria, $4^{\text {th }}$ Naz.Conference, May, 2005

18.Price, C.Basics of speech therapy. St. Nicholas Kliment Ohridski”; Sofia, 2012

19.Anderson JD, Pellowski M, Conture EG. Linguistic variablesinchildhoodstuttering: Speech-language dissociations. Journal of Fluency Disorders. 2005;30:125-148.
20. Bloodstein, O. Stuttering: The Searchfor a Causeand Cure. Allyn\&Bacon, 199556

21.Craig, A., Hancock, K., Tran, Y., Craig, M., Peters, K. (2003). Anxiety level sin people who stutter: A randomized population study. Journal of Speech, Languageand Hearing Research, 46, 1197-1206.

22. Gordon W. Blood, G. W., Blood, I. M., Maloney, K., Meyer, C., Qualls, C., D., Anxiety level sinadolescentswhostutter, Journal of Communication Disorders 40 (2007) 452-469 